\title{
Migrant Children at School: How Gender Influences Adaptation
}

\author{
T. I. Monastyrskaya ${ }^{1}$, N. L. Mikidenko' ${ }^{1}$ G. V. Toropchin ${ }^{2, *}$, S. P. Storozheva ${ }^{1}$ \\ ${ }^{1}$ Department of Sociology, Psychology and Political Science, Siberian State University of Telecommunications and Information \\ Sciences, Russia \\ ${ }^{2}$ Department of Foreign Languages (Engineering Programmes), Faculty of Humanities, Novosibirsk State Technical University, \\ Russia
}

Received February 18, 2020; Revised May 19, 2020; Accepted May 27, 2020

Copyright ( 02020 by authors, all rights reserved. Authors agree that this article remains permanently open access under the terms of the Creative Commons Attribution License 4.0 International License

\begin{abstract}
The ethical issues of adaptation of ethnic migrant children retain their relevance taking into account the high influx of migrant labourers during the previous decade both in the territory of Russia as a whole as well as Siberia. The authors explore the problems that these students face as they relate to gender and their sociocultural and educational adaptation in the learning environment of a secondary school. Considering international and Russian experience of gender studies in this field, the authors concentrate on the differences in the process of adaptation in girls and boys. Based on the analysis of the result of an original sociological study, the paper characterizes gender tendencies in a subjective assessment of school performance in migrant students, organization of additional activities within the curricula and elective courses, camps and workshops, and involvement in various celebrations. An evaluation of the correlation between cultural and educational practices of the host society and traditional models of upbringing boys and girls has been made. The authors draw attention to the necessity of undertaking various and different approaches in terms of assisting each gender to adapt to the learning environment. The findings are useful for teachers, social workers and school psychologists working with migrant students.
\end{abstract}

Keywords Ethnic Migrant Children, Gender Aspect, Sociocultural Adaptation

\section{Introduction}

Many major Russian cities remain attractive to migrant families. Along with their parents, children also become immigrants, with many of those planning to obtain a basic professional education in Russia. Schools are the space in which ethnic migrant children adapt to their new learning environment.

Cultural stereotypes and norms defining the organisation of various spheres of life are the main factors influencing the children's adaptation. Gender perceptions and stereotypes play key roles in this. Differences between perceptions of masculinity and femininity, gender norms, interaction with their peers, as well as individual language, social, psychological and cultural peculiarities are all important factors in a migrant student's adaptation at school. As such, a traditional view of women's roles can become a reason for contradictions between migrant girls and their parents in the process of integration in the culture of the host society. This is why in organising constructive help in sociocultural adaptation one must pay attention to the peculiarities of gender representations and stereotypes of the countries of origin and their manifestations in children's school educational practices.

Within this study, the authors have attempted to single out the main clusters of gender issues connected with sociocultural and educational adaptation of migrant children, as discussed by international and Russian scholars. They have also outlined certain gender peculiarities of migrant school pupils' adaptation in the learning environment of metropolis schools based on data analysis.

The research of migrant children's adaptation in the school environment (especially in a metropolis) is limited, reflected by the lack of research in schools, lack of statistical data and other problems.

The role and relevance of our study are underlined by a literature review of the recent research in the field. 


\section{International Experience in Gender Studies of Migrant Children's Adaptation}

In the international literature, gender issues in terms of teaching migrant children has repeatedly been touched upon by multiple authors (Americans and Europeans in the first place). The International Organization for Migration (2017) points out that gender identity often becomes the reason for migration per se and influences the forming-up of social relations, integration in the host society and employment. Recommendations of the Advisory Committee on Equal Opportunities for Women and Men acknowledge that women have less access to education (European Commission, 2018). This fact is also proved in the study by A. Llácer et al. (Llácer, Zunzunegui, del Amo, Mazarrasa \& Bolůmar, 2007) This is predetermined by traditional roles played by women in the community, as well as trivial absence of necessary information. The Committee therefore recommends to give special attention to the inclusion of girls in the social activities (European Commission, 2018).

It is necessary to give an outline of the European experience in terms of research in the given area. Norwegian scholars scrutinize these problems based on a case study of their country which is widely known thanks to their proactive inclusion of migrants into the social life of the host community. Researchers have come to a conclusion that girls from migrant families normally outperform boys in terms of academic progress before they are 16 years old: the trend changes starting with this age (Bratsberg, Raaum \& Røed, 2010). The book 'The Impact of Immigration on Children's Development' edited by C.T. Garcia Coll mentions the fact that studies undertaken in Italy have proved that male students are less emotionally stable compared to girls (Dimitrova \& Chasiotis, 2012). It is primarily about children that moved to the country from Albania and Serbia. Also male students turned out more prone to aggression and less socially adaptive. Such data is received as result of surveying both children and their teachers.

Analysis of the gender aspects of adaptation in migrant children from Ecuador in Italy displays that girls achieve better grades and also have a better social capital thanks to retaining connections with their families and ethnic communities, whereas boys' social connections are of rather a chaotic nature (Ravecca, 2010).

French experts Y. Brinbaum and A. Kieffer (2009) quote statistics according to which migrant children get seriously behind their peers born in France. The percentage of immigrant boys who are one year behind their counterparts us at $35.3 \%$ (it is $15.1 \%$ for locals). With girls it is lower being at $25.5 \%$ (it is $11.7 \%$ for those born in France). The number of young males without a college or university diploma is twice as high as in young females ( $24 \%$ vs $12 \%)$. As a comparison, figures for those born in France are as follows: 9\% for males and 5\% for females.

Some law enforcement practices existing in certain states could also be of interest. For instance, there is a special norm set in Finnish law: enrollees choosing majors with less than $30 \%$ of students of the same sex can obtain extra points when acquiring vocational education (Opetushallitus, 2005).

American researchers also draw their attention to the role of gender factor in adaptation of the migrant children in the host society. The importance of sexual identity in the process of a migrant child's familiarization with the new environment is highlighted in a publication by Board on Children and Families (Board on Children and Families, 1995). D.B. Qin (2006), from Michigan State University, points out that in the U.S., where representatives of various ethnic groups have long coexisted, it is girls that are in a more privileged position from an educational standpoint. The researcher argues that it is explained by factors such as a high level of expectations from their parents, socialization in the home environment, relationships at school as well as cultural assimilation and adaptation. The author studies in more detail the behaviour patterns of Chinese adolescents who moves to another country depending on their gender (Qin, 2009). As such, it is found that girls and boys cope with the pressure of the host society and their families in different ways.

It is important to note that the differences displayed by boys and girls of school age affect multiple parameters of the labour market in the long run. This is especially relevant for the United States, where immigration policy banning the deportation of illegal immigrants who came to the U.S. before their legal adulthood was compromised after the Trump administration took office. In accordance with the paper by Migration Policy Institute, $83 \%$ of these men were employed as of 2014 (the average percentage was at $79 \%)$. An inverse trend was found for women: this figure was at $67 \%$ whereas the average was at 73 , which again reveals a certain gender gap (Capps, Fix \& Zong, 2017).

The work 'Acculturation and Immigrant Children: Implications for Educators' by A. Kurtz-Costes and E.P. Pungello (2000) proves that girls in immigrant families from third world countries are far more prone to undertaking family responsibilities and more seldom strive for tertiary education. In this case, the authors suggest that the instructors should give up speculations and stereotypes of professional communication with male and female students, as in every case there exists individual peculiarities characteristic of family relationships.

D.B. Qin (2006) underlines that the gender issues have previously and undeservedly been neglected in sociology studies focusing on problems facing migrant families, even though one fifth of children in American schools come from immigrant families. It is necessary to keep in mind 
that the term 'immigrant children' also embraces second generation of migrants, i.e. the term includes those born both outside the recipient country and in it. As the most general conclusion of the studies D.B. Qin mentions, the fact remains that male migrant pupils fall behind their female counterparts in terms of academic progress.

Internal migration is considered in the paper by C. Goodburn (2015) based on the case study in the city of Shenzhen, China. The researcher focuses on countryside girls who move to a large city with their parents and enrolled into a primary school. The findings show that the parents have special expectations of their daughters which are different from that of their sons. Apart from that, the author also notes the positive influence of such a situation on the girls' mothers, whose motivation also improves.

After analysing several foreign studies of migrant children's adaptation and taking gender issues into account, we outline the following problems as discussed by the authors and conclusions made by them.

In terms of academic adaptation:

- Migrant children fall behind in academic progress from their local counterparts;

- It is necessary to provide migrant girls with access to education;

- Migrant boys of the age up to 16 fall behind in terms of academic adaptation.

In terms of psychological adaptation:

- Migrant male students tend to display lesser emotional stability;

- Migrant boys are more prone to develop aggression.

In terms of social adaptation:

- Migrant boys tend to display less social adaptability;

- Migrant girls possess a better social capital.

\section{Russian Experience in Gender Studies of Migrant Children's Adaptation}

In the recent decades in Russia, academics have given significant attention to problems of adaptation and integration in migrant children.

Among significant works to be mentioned in the field of migrant children's adaptation and integration are studies by the following groups of authors: D.A. Aleksandrov, V.A. Ivanyushina, V.V. Kostenko, S.S. Savelyev, K.A. Tenishev 'Migrant children's Position in St. Petersburg' (2011) and V.P. Zasypkin, G.Ye. Zborovskiy, and Ye.A. Shuklina 'Issues of migrant children's education and adaptation in figures and dialogues' (2012) in Khanty-Mansiisk autonomous district. They can be singled out as having an elaborate conceptual framework, a breadth of problems under consideration, and quality analysis tools. In the mentioned studies, gender peculiarities of school pupils' adaptation are also noted. However, they are touched upon indirectly, in their connection with other, more general problems.

Gender differences in communication and social community are based upon fundamental principles deeply rooted in culture, mentality and traditions. It is possible to say that male and female cultural traditions have certain differences in concepts of social relations structure (Serebryanskaya, 2011). Gender aspects of the migrant adaptation process are studied by O.V. Krasilnikova based on the case of Russian migrant adaptation behaviour in Germany (Krasilnikova 2014). The author underscores the differences in male and female practices of adaptation making a conclusion on a better adaptability in females and successfulness of their strategies. I.B. Britvina also underlines a higher efficiency in migration behaviour strategies used by female migrants in comparison to those used by men. According to the author, 'females using certain gender strategies do not overreact to a lower social status, change of trade or workplace as much as men and have a higher level of satisfaction from the results of migration' (Britvina, 2006).

A study by T.I. Monastyrskaya, Ye.V. Kuzina and A.A. Kovalyova (2016) reflects issues of sociocultural adaptation of migrant students on the basis of a school with a prevalent number of migrant students. Such a ratio of the migrant students and students coming from the host society allows one to concentrate on different aspects of students' sociocultural adaptation, including gender. Gender peculiarities are considered among the major factors of peers' influence and inclusion in modern youth practices (Omel'chenko \& Andreeva et al., 2010).

The issues connected with children's education and healthcare is reviewed in a study devoted to female migrants (Zhenshchiny-migranty iz stran SNG v Rossii, 2011). Authors point out that migrant children communicate how well their parents are adapted to living in a new country. Gender relations in migrant families affect children's upbringing and behaviour models. As such, girls who come from Central Asian countries are notably more industrious and helpful. This is not always the case with girls who were born in another country and assimilated to the environment.

Research by specialists from Higher School of Economics based on the material of St. Petersburg points out that gender is one of the important parameters defining the academic progress of a child, including children from immigrant families. As such, according to authors' observation, in general boys study worse (Aleksandrov \& Ivaniushina et al., 2011). Another aspect they pay attention to is as follows: in terms of forming social connections among migrant children, belonging to the same gender plays a more important role than belonging to the same culture. This phenomenon is defined as gender homophily.

M.I. Kokhanovskaya stresses that girls and boys from migrant families adapt in a school environment differently 
and encounter specific hardships: girls have more difficulties in social and psychological adaptation, whereas for boys it is the case with cultural adaptation. Another problem is a low assessment of girls' academic future, as they can skip classes quite frequently, helping around the house or looking after their younger siblings (Kokhanovskaya 2019).

L.N. Azarova pays attention to the difficulties that most pedagogues working with migrant children met. These are connected with the gender roles in various cultures. The author points out that "encountering the culture of ethnic groups, where differences in the traditional upbringing of boys and girls are more pronounced than in the pedagogues' personal culture, most of the participants questioned the concept of a gender-based approach", solving the problem of the degree of "teacher's intervention" into changing traditional cultural limitations in this regard (Azarova 2019).

D. Poletaev (2012), researching problems of migrant children's adaptation in Moscow schools, includes in his study gender aspects of adaptation along with the statement of a wider range of questions: command of the Russian language as a key factor to adaptation, problems with enrollment into schools, working with classes having a certain percentage of migrant children, working with teaching staff and parents. The author singles out the gender aspect of problem with migrant children's relations in the school collective and teaching staff: a sustaining orientation to gender superiority displayed by migrant boys given losing traditional behaviour norms.

Analysing issues of migrant children's adaptation in the educational system, Ye.I. Surovtsova (2014) states that the necessity of using gender approach is predetermined by girls' and boys' peculiarities in terms of differences in the duration and techniques of absorbing training content, organizing rest and leisure, relationships with peers. As such, according to the researcher's findings, girls in general surpass boys in intellectual development, being more obedient and assiduous. Girls progress in the humanities (including the Russian language) faster and they speak more eloquently compared with boys. Boys are more dynamic (especially during space time), display quantitative skills more often, are better in tasks requiring spacial reasoning, are more successful when it comes to exact sciences, however, they acquire oral information worse than girls (Surovtsova, 2014). The author pays attention to the problems in relations of schoolboys and schoolgirls from migrant families connected with the boys' behavioural attributes. Boys who do not like playing with girls, can insult or even hit them. Substantiating peculiarities of pedagogical strategies with regard to boys and girls, Ye.V. Surovtsova (2014) underlines the role of collaborative play (including those where change of leaders is possible) for establishing friendly relationships between children, importance of trust and justice in communication with migrant boys, as well as need to teach them respect for women (girls in particular).

The ideals of Russian schoolchildren's gender socialisation have been studied by L.V. Shtylyova. Comparing the conditions of gender socialisation in Russia and Western European countries as well as in Canada, the author captures a gender pattern in parents' assessment with regard to communication with children in Russian families. Among other conclusions are a significant gap in the requirements to girls and boys (requirements to girls are considerably higher and more numerous), "domination of traditional plots from the gender point of view in children's literature, cartoons and TV shows, traditionalism in boys' and girls' upbringing in Russian schools” (Shtyleva 2019).

Migrant children's specificity consists in the fact that they, in their everyday experience, encounter various spaces which are quite different from each other (Russia and Motherland, home and host society, school and the outside); experiences (their affined/ethnic environment and others), lifestyles, culture patterns (parents and peers) and are, at that, surrounded by dominating discourses of xenophobia and 'formal tolerance' at school. In such circumstances gender differences become an additional factor of adaptation, since gender behaviour models intrinsic to migrants and their children can conflict with the gender behaviour models accepted in the host society (Sabirova, Andreeva, 2014).

On the whole, studies reviewing gender aspects of adaptation note a crucial significance of the 'gender' category in organizing the academic activity since school in many respects forms perception of life strategy, professional self-determination, access to resources and power based on social and sexual orientation. This is why it is necessary to consider and form communication in the process of education with an allowance for the communicator's gender.

It is obvious that among the most accepted gender directives are conformity with male and female modes of behaviour and culture forms, in accordance with which communicative relations among subjects are formed. In fact, gender position in communication depends on a set of factors allowing an individual to realize their own gender roles or identify their gender.

On the whole, Russian studies of gender aspects of migrant children's adaptation touch upon a wide range of major problems:

- language adaptation and sociocultural adaptation;

- training and education;

- $\quad$ problems of tolerance and intolerance;

- influence of gender peculiarities on the inclusion of migrant children in modern youth practices etc.

Russian researchers' findings coincide with those by foreign researchers: on average, boys perform worse than girls; female migrants demonstrate a higher efficiency in terms of migration behaviour strategies. The necessity of using a gender-based approach to migrant students is 
predetermined by boys' and girls' peculiarities in terms of differences in duration and methods of training material acquisition, organizing rest and leisure, and in relationships with peers.

\section{Materials and Methods}

\subsection{Research Methodology}

The aim of the applied sociological study is to single out and describe gender-based peculiarities of adaptation in international ethnic migrant children within the school environment.

The following problems are to be addressed in the study:

1. Singling out differences in school practices of adaptation in girls and boys;

2. Defining the influence of gender as a factor on the attitude towards the education and academic progress;

3. Defining boys' and girls' preferences in terms of choosing extracurricular activities at school;

4. Describing boys' and girls' inclusion in the extracurricular events and their corresponding thematic preferences.

\subsection{Research Hypotheses}

1. There exist certain gender peculiarities in the practices of adaptation in the school environment for children from international ethnic migrant families (attitude towards education, inclusion in school activities, communications in the educational environment as well as adaptation strategies).

2. When choosing extracurricular activities, girls and boys mostly rely upon the traditional femininity and masculinity role models.

3. Girls are more prone to encounter difficulties in social and psychological adaptation whereas for boys the process of cultural adaptation is more difficult.

\subsection{Research Stages and Sampling}

The study is conducted in two stages. The first stage took place in 2016-2017 and did not presuppose the study of the gender aspect of sociocultural adaptation in international ethnic migrant children. At the second stage (2018), secondary data analysis was used as a research strategy. Secondary data analysis was conducted to mark out gender differences in all major groups of indicators used in the first stage of the study. Those include attitude to education, inclusion in the school activities, communication in the educational environment and adaptation strategies. Special attention was paid to students' curricular and extracurricular activities as well as problems in learning Russian.

The study was carried out in secondary schools in Novosibirsk with support from the Department of Education field office, as previously agreed with administration of the schools and children's parents. 26 Novosibirsk schools were chosen from the list of city schools. The data was collected based on surveying schoolchildren using individual questionnaires at school. A total of 237 (61.1\%) boys and 151 (38.9\%) girls took part in the survey. As of 2016-2017, the respondents were students of $1^{\text {st }}$ to $11^{\text {th }}$ grades in secondary schools. Most of those surveyed studied in $5^{\text {th }}$ to $9^{\text {th }}$ grades. The sampling has a purposive character and is enough to draw conclusions on the topic under consideration.

\subsection{Questionnaire Structure}

The sociological instrument (namely, the questionnaire) was designed by T.I. Monastyrskaya and A.A. Kovaleva (Monastyrskaya \& Kuzina et al., 2016) and tried out based on the Municipal budget general education institution "Secondary education school №66" of Novosibirsk. The school was of interest as a testing platform since at the time of the survey international migrant students represented $64 \%$ of the students.

The designed sociological instrument (questionnaire) included closed-ended radio-type questions, multiple-choice questions and open-ended questions, which made it possible for us to cover the corresponding indicators and descriptors.

\subsection{Analysis and Interpretation of the Data}

In order to analyse the data, we used statistical methods (contingency tables and Pearson correlation). When describing the process of adaptation and detecting the gender peculiarities of international migrant children's adaptation, we also use interpretative methods of information analysis. Interpreting the results of the study, we rely upon social constructivist approach. In this approach, gender socialisation of an individual is understood as a process of integration into the society based on certain values, stereotypes and norms defined by social institutions. Gender stereotypes reflect differences in roles in activities, perceptions of masculinity and femininity. Gender stereotypes, norms and perceptions are adopted in cultural and social interaction, are confirmed by social practices and have an impact upon various fields of an individual's activity. 


\section{Results and Discussion}

\subsection{Countries of International Migrant Children's Origin}

Most of the international migrant students arrive from CIS countries. The range of the countries from which international migrant children have arrived is presented on Fig. 1 and 2.

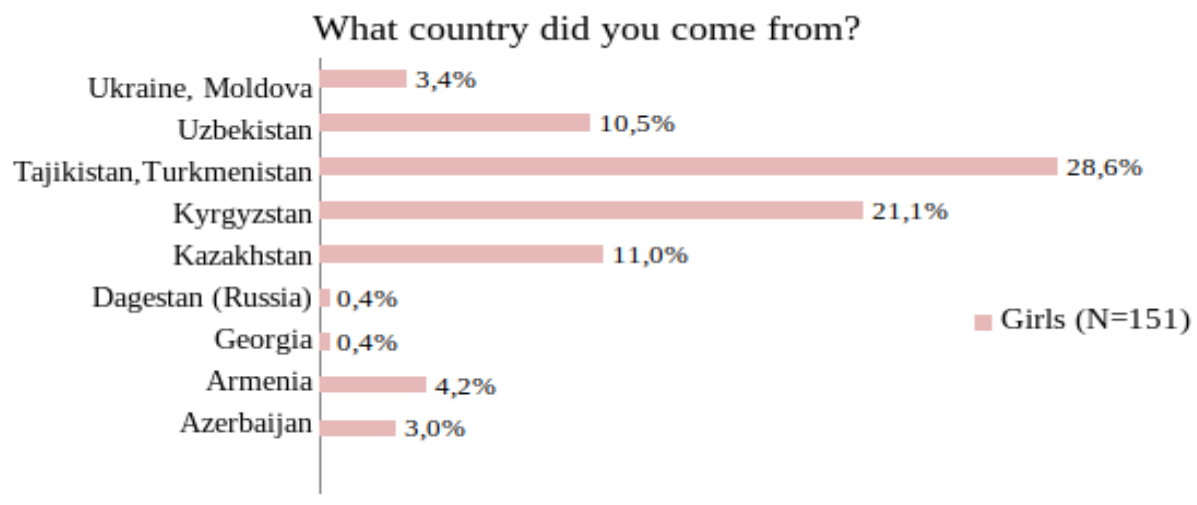

Figure 1. Gender distribution of respondents based on their answers to the question 'What country did you come from?' (females)

Most females come from the following countries: Tajikistan, Turkmenistan (28.6\%), Kyrgyzstan (21.1\%), Kazakhstan (11\%) and Uzbekistan (10.5\%). Fewer respondents indicate such countries as Armenia (4.2\%), Ukraine, Moldova (3.4\%), Azerbaijan (3\%), Georgia (0.4\%).

What country did you come from?

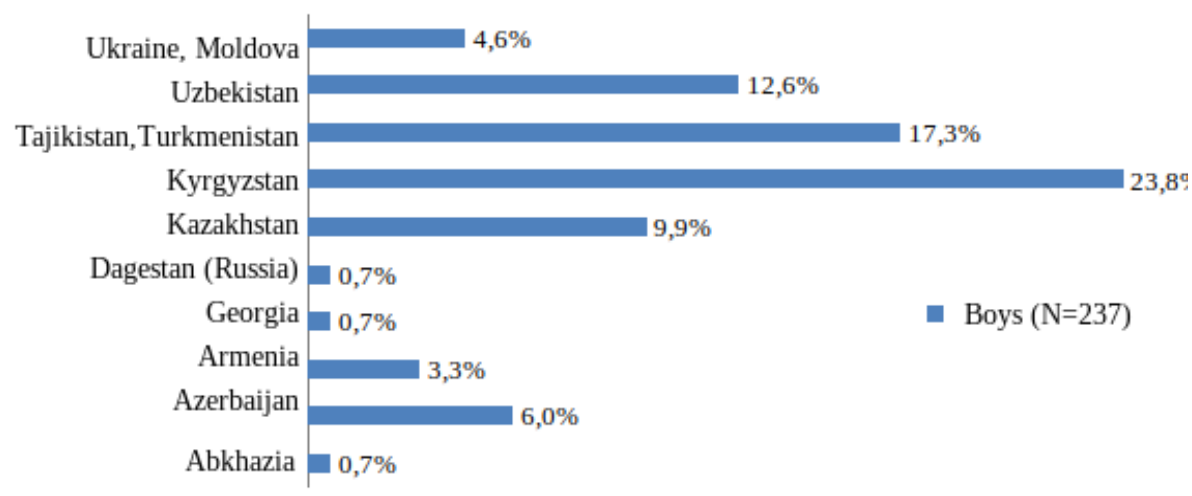

Figure 2. Gender distribution of respondents based on their answers to the question 'What country did you come from?' (males).

Most boys come from the following countries: Kyrgyzstan (23.8\%), Tajikistan, Turkmenistan (17.3\%), Uzbekistan (12.6\%), Kazakhstan (9.9\%). Fewer respondents indicated such countries as Azerbaijan (6\%), Ukraine, Moldova (4.6\%), Armenia (3.3\%), Georgia and Abkhazia (0.7\%). 


\subsection{Defining the Difference in Boys' and Girls' Answers}

After analysing the body of data in a number of questions it become possible to single out the differences in boys' and girls' answers (Table 1 ).

Table 1. Differences in boys' and girls' answers

\begin{tabular}{|c|c|c|}
\hline \multicolumn{3}{|c|}{ Correlations } \\
\hline & & Gender \\
\hline \multirow{3}{*}{$\begin{array}{l}\text { What grades do you get the } \\
\text { most often? }\end{array}$} & Pearson correlation & $0,167^{* *}$ \\
\hline & Value (2-tailed) & 0,001 \\
\hline & $\mathrm{N}$ & 381 \\
\hline \multirow{3}{*}{$\begin{array}{l}\text { Who helps you with } \\
\text { classwork/homework? }\end{array}$} & Pearson correlation & $-0,108^{*}$ \\
\hline & Value (2-tailed) & 0,034 \\
\hline & $\mathrm{N}$ & 383 \\
\hline \multirow{3}{*}{$\begin{array}{l}\text { What extracurricular } \\
\text { activities do you have at } \\
\text { school? }\end{array}$} & Pearson correlation & $0,156^{* *}$ \\
\hline & Value (2-tailed) & 0,007 \\
\hline & $\mathrm{N}$ & 292 \\
\hline \multicolumn{3}{|c|}{ **. Correlation is significant at the 0.01 level (2-tailed). } \\
\hline \multicolumn{3}{|c|}{ *. Correlation is significant at the 0.05 level (2-tailed). } \\
\hline
\end{tabular}

According to the results obtained the 'gender' variable has significant correlations with the following variables: 'What grades do you get the most often?', 'Who helps you with classwork/homework?' and 'What extracurricular activities do you have at school?' The data demonstrates that the answers of the pupils surveyed to the given questions have a connection with the children's gender. The level of correlation significance between the 'What grades do you get the most often?' question and the gender as well as the question 'What extracurricular activities do you have at school?' and the gender is 0.01 . Correlation between the 'Who helps you with classwork/homework?' question and the gender is significant at the 0.05 level. As such, we can conclude that girls and boys have different grades at school. Children's gender also affects the helpers in doing homework and choosing extracurricular activities at school.

\subsection{Gender Peculiarities in Migrant Students' Self-evaluation of School Performance}

Gender peculiarities manifest themselves in the subjective evaluation of children's school performance. The difference in the subjective evaluation of boys' $(\mathrm{N}=235)$ and girls' $(\mathrm{N}=148)$ school performance is provided in Table 2.

The respondents are supposed to answer the question: 'What grades do you get at school?' At first the question is not standardised, and the schoolchildren formulated the answers as they wished. When processing the answers, these are merged into groups 'A's', 'A's and B's', 'B's', 'B's and C's', 'C's', 'C's and F's', 'A's and C's' and 'B's and $\mathrm{F}$ 's'. In order to find out the correlation among the 'gender' and 'performance evaluation' attributes, the groups are further combined ('A's' and 'A's and B's', 'C's and F's' and 'C's'). Quite a large group of children (3.8\%, $\mathrm{N}=15$ ) define their performance as 'A's and C's' or 'B's and F's'. Due to the uncertainty of this evaluation this group is excluded from calculations.

Table 2. Gender peculiarities in the distribution of answers to the question 'What grades do you get at school?'

\begin{tabular}{|c|c|c|c|}
\hline $\begin{array}{c}\text { Subjective evaluation of school } \\
\text { performance }\end{array}$ & Boys & Girls & Total \\
\hline 'A's and B's' (N persons) & 54 & 57 & 106 \\
'A's and B's' (\%) & $24.0 \%$ & $40.4 \%$ & $30.3 \%$ \\
Adjusted residual & -3.3 & 3.3 & \\
\hline 'B's' (N persons) & 30 & 18 & 48 \\
'B's' \% & $13.3 \%$ & $12.8 \%$ & $13.1 \%$ \\
Adjusted residual & 0.2 & -0.2 & \\
\hline 'B's and C's' (N persons) & 99 & 50 & 149 \\
'B's and C's' (\%) & $44.0 \%$ & $35.5 \%$ & $40.7 \%$ \\
Adjusted residual & 1.6 & -1.6 & \\
\hline 'C's' (N persons) & 42 & 16 & 58 \\
'C's' (\%) & 18.7 & 11.3 & 15.8 \\
\hline Adjusted residual & 1.9 & -1.9 & \\
\hline Total (N persons) & 225 & 141 & 366 \\
Total (\%) & $100 \%$ & $100 \%$ & $100 \%$ \\
\hline
\end{tabular}

The results enumerated testify the fact that boys are apt to evaluate their school performance lower than girls. However, in order to consider this phenomenon as adaptation peculiarities, it is necessary to compare results with the subjective evaluation of schoolchildren's performance on the whole, irregardless of the migration aspect. This fact is emphasised by other researchers (Starostina, 2013). Apart from that, some studies of migrant children's school performance underline that the migration factor positively influences school performance and motivation (Aleksandrov \& Ivanyushina et al., 2011).

\subsection{Gender Aspects in Extracurricular Activities}

As for the question 'Do you visit activity clubs or additional courses at school?', the distribution of the answers shows that boys and girls are involved in some extracurricular activities. However, the choice of activity clubs, extra classes etc. named by the respondents demonstrates the peculiarities of choice made by boys and girls. Boys prefer joining sports sections (including various kinds of martial arts - karate, sambo, taekwondo, aikido, group sports - football, volleyball and basketball, as well as boxing, track-and-field athletics and chess) and military and patriotic classes (Sledopyt, Military School etc.) Among girls' interests there are music, singing, dancing, acting as well as fine and applied arts (bead weaving, sewing and dough art etc.) The distribution of answers is represented on Figure 3. 
What activity clubs or additional courses do you have at school?

$$
\begin{aligned}
& \text { Military and patriotic/cultural and historical classes } \\
& \text { Classes in exact and natural sciences } \\
& \text { Foreign language classes (English, French) } \\
& \text { Arts and crafts } \\
& \text { Music classes (incl. singing), dancing, acting } \\
& \text { Sports } \\
& \begin{array}{|c|}
\hline 1,2 \% \\
6,1 \% \\
\hline 4,2 \% \\
\hline 4,2 \% \\
-2,4 \% \\
4,2 \% \\
\hline 3,2 \% \\
\hline 5,8 \% \\
\hline 2,0 \% \\
\hline \multicolumn{1}{|c|}{7,5 \%} \\
\hline \\
\hline
\end{array}
\end{aligned}
$$

Figure 3. Answers to the question 'What activity clubs or additional courses do you have at school?'

It is necessary to point out that more than a half of boys (65.4\%) and girls (61.9\%) do not visit any clubs or courses. It is not always connected with the children's reluctance to participate in these clubs after study hours, being possibly linked with goals and traditions in migrant families.

\subsection{Gender Aspects in Choosing Local Language Learning Strategies}

The command of the Russian language plays an important role in the sociocultural adaptation. Migrant students have to study Russian additionally, as school lessons are not enough for fast adaptation in another language environment. At that, girls and boys choose different strategies for language learning (Figure 4).

How do you study the Russian language additionally?

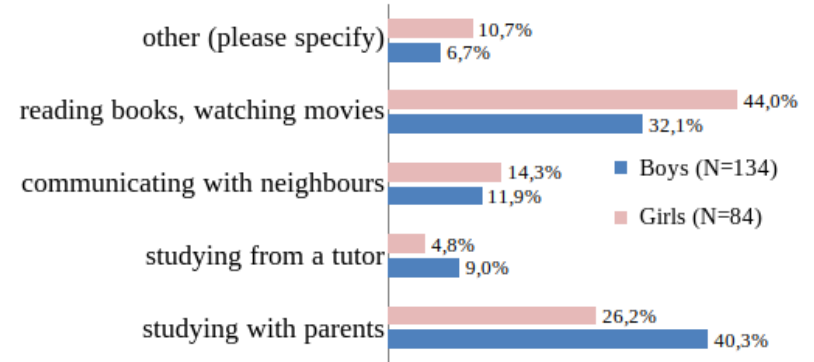

Figure 4. Distribution of answers to the question: 'How do you study the Russian language additionally?’ ( $\mathrm{N}=218,134$ boys and 84 girls).

Girls display more independence in learning the Russian language by reading books and watching movies in Russian (44\%) more than boys, communicating with their neighbours in Russian (14.3\%), and finding other ways of learning the language more often than boys (10.7\%). Boys prefer to resort to their parents' help (40.3\%) and private tutors' $(9 \%)$ services more often than girls.

\subsection{Level of independence in preparation}

Girls' level of independence in preparing home tasks is also higher than that of boys (Figure 5).

$72.5 \%$ of girls cope with their homework themselves, without resorting to anyone's help. Male respondents coping with their homework independently amounted to $62.8 \%$. Boys resort to their parents' and classmates' help.

Who helps you in coping with your classwork/hometasks?

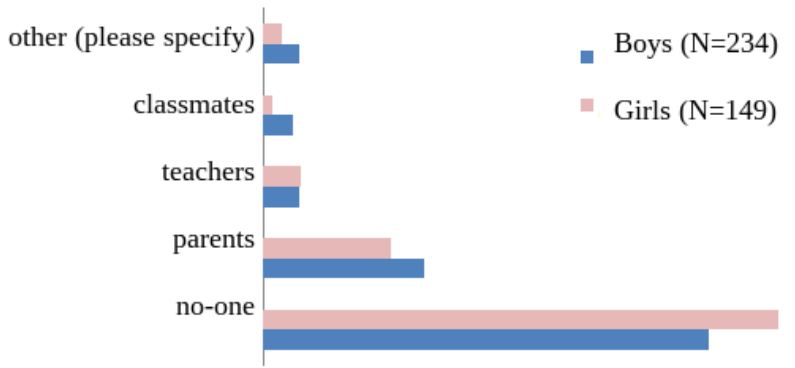

Figure 5. Distribution of answers to the question 'Who helps you in coping with your classwork/hometasks?' (it was possible to choose no more than two answers).

\subsection{Gender Peculiarities in Adaptation and Leisure Activities}

For detecting gender peculiarities of adaptation, it is ways of organizing free time and children's inclusion in the festive culture that are of special interest (Fig. 6). Girls display a higher activity in participating in school festivities. $Z=|2,8|$, which is $\geq|1,99|$ and proves association of the attributes on the assumption of that in 0 $(.0 \%)$ cells expected frequency is lower than 5 . The level of correlation significance has values to 0.05 , therefore, the probability of the assumption that the links obtained are not accidental is high. Differences in festivals, which respondents consider to be significant and in which they participate, are also exposed. As such, in girls' answers Mother's Day was named as one of the most popular festivities.

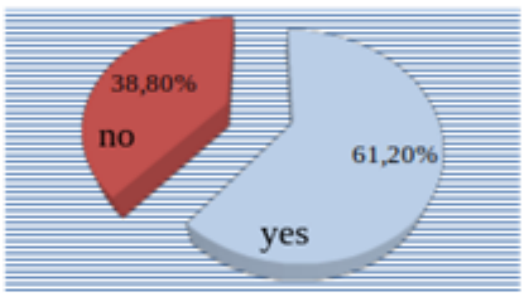

Do you participate in school festivities? $(\mathrm{N}=237)$

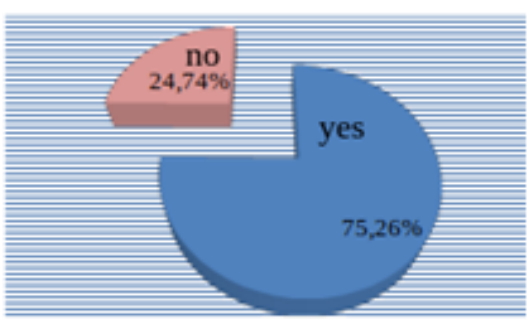

$$
\begin{aligned}
& \text { Do you participate in school } \\
& \text { festivities? (Girls, N=237) }
\end{aligned}
$$

Figure 6. Distribution of answers to the question 'Do you participate in school festivities?' 


\subsection{Social Circle and Living Strategies}

No significant differences are singled out in boys' and girls' answers to other questions of the study. As such, in particular, both boys (88.4\%) and girls (92.6\%) mostly like the school where they study. $89.7 \%$ of boys and $89.2 \%$ of girls point out that teachers in their school give equal attention to all students. Circle of contacts forms quite similarly in migrant boys and girls: $12.8 \%$ boys and $12.1 \%$ girls; $70.2 \%$ boys and $69.1 \%$ girls communicate with all children (without discerning natives of their country, other countries and students from the host country); $1.3 \%$ girls and $1.3 \%$ do not communicate with anyone at school. No significant differences are singled out in girls and boys in strategies of learning and living in the new country. $69.8 \%$ boys and $68.5 \%$ girls consider they will stay in Russia. $29.1 \%$ boys and $31.8 \%$ girls plan to continue their education in the $10^{\text {th }}$ and $11^{\text {th }}$ grades, at that $19.1 \%$ boys and $19.1 \%$ girls think of entering a university in the future.

The study conducted shows that acquiring cultural norms and traditions of the host society in migrant girls and boys can have different channels of influence. Interaction with the agents of sociocultural adaptation can also be different. The authors succeeds in singling out gender differences in extracurricular activities of migrant students, which need attention for organizing a more effective support for the process of sociocultural adaptation in migrant students.

\section{Conclusions and Recommendations}

1. Ethnic migrants retain a high level of credence to Russian schools as a social institution. The study conducted shows that this assessment is quite fair, and the education system plays an important role in the sociocultural adaptation of international ethnic migrant children.

The findings of our research confirm conclusions by A.Ya. Makarov regarding the presence of 'high adaptive potential' in the environment of secondary school for migrants which have an interest in learning the Russian language and culture, most of them being aimed at a more active interaction with the representatives of the ethnic majority, obtaining a degree and working in our country' (Makarov, 2010). That said, such a group of children, according to our study data, is equally represented by both girls and boys. However, it is difficult to make a conclusion regarding the gender differentiation of such potential based on just one sociological study.

2. The study shows that the adoption of cultural norms and traditions of the host society can have different pathways in boys and girls. Interaction with the agents of sociocultural adaptation can also be different. The analysis of the results helps us to mark out statistically significant differences in boys' and girls' answers. This fact allows us to draw an inference about the existence of gender peculiarities in school adaptation for migrant children, which confirms the hypothesis developed above. We also single out gender differences in extracurricular activities of migrant children, which have to be kept in mind in order to facilitate the migrant students' sociocultural adaptation more effectively.

It is necessary to form educational and extracurricular activities considering gender differences to ensure a more successful adaptation of migrant students. It is important to offer a broad range of opportunities in education as well as any other cultural and social activities to migrant girls.

3. When choosing extracurricular activities, boys and girls mostly rely on traditional models of masculinity and femininity. When choosing extracurricular activities at school, boys prefer sports, military and patriotic hobby groups, which presupposes the display of traditionally perceived masculine qualities: ambition, self-sufficiency and independence. Girls prefer activities connected with music, dances, foreign languages, arts and crafts (beadweaving, sewing and dough art). Mother's Day and International Women's Day are the school events most frequently singled out by girls. This is mostly related to traditional feminine characteristics: aptness to household activities, readiness to take care of the family, emotional sensitivity, tenderness, acquiescence and even defenselessness (Shtyleva, 2019).

4. The research is conducted based on the supposition that girls experience difficulties in social and psychological adaptation, whereas boys have more difficulties undergoing the process of cultural adaptation. The first thesis proved partly correct. Indeed, girls are less likely to resort to help in completing assignments, whereas boys are more likely to resort to teachers' and classmates' help. Perhaps this is due to social and psychological difficulties that girls tend to have (European Commission, 2018). However, this strategy of behaviour can be connected with the fact that girls are normally more independent and have a better command of the host country language. It can also be related to the traditions of the country of origin where females do not supposedly have a wide circle of communication.

The second part of the hypothesis turned out to be right. Boys are less likely to participate in school events based on the cultural practices of the host society (39\% of the boys do not do so). In order to stimulate cognitive and cultural interest in boys, it is necessary to find new forms of cooperation with them, oriented towards achieving success and new opportunities in the host society.

5. Considering a lower adaptive potential of boys compared to that of girls, it is necessary to pay special attention to the pedagogical strategies of organizing support for boys' adaptation. Boys need to be offered consultations for acquisition of learning material more actively, supporting a connection with their parents, since it is they that boys most often resort to asking for help in their studies. Boys also need to be involved in extracurricular 
activities and inculcated a sense of responsibility and behaviour self-control.

6. No matter what cultural traditions of the countries of migrant origin and family gender traditions are, boys and girls should accept the social and cultural norms of their host country, where most of them would like to stay. The educational environment of secondary schools has the largest potential for migrants children's sociocultural and educational adaptation. School teachers play an important role in this process. It is necessary to assist the teachers to gain new competencies (such as taking into account gender differences and the traditional cultural norms of migrant children's countries of origin) through the additional education system. In children, the process of adopting new values and norms is quicker than in adults, but it is not a permanent process, which is why teachers have to display not only patience, but also creativity in developing new forms and methods of migrant children's involvement into the cultural life of their school and city.

7. This study shows the importance of self-evaluation of adaptation practices by the migrant students on the whole, as well as the importance of analysing such practices from a gender standpoint.

8. We do not encounter significant differences in boys' and girls' opinions as to their life strategies. Nevertheless, we consider that this question has to be examined more thoroughly in a separate study. This study will allow us to find out how gender stereotypes act as a barrier in the process of sociocultural adaptation and integration to a host society.

\section{Acknowledgements}

We express our gratitude to Laura Huffman for professional advice and helpful suggestions.

\section{REFERENCES}

[1] Aleksandrov, D., Baranova, V., Ivaniushina, V. (2012). Migrant Children in Russia. I. Migration, Ethnicity and Segregation in St. Petersburg. Available at: https://www.hse.ru/pubs/share/direct/document/74932475.

[2] Antman, F.M. (2012). Gender, Educational Attainment, and the Impact of Parental Migration on Children Left Behind. Journal of Population Economics, 25(4), 1187-1214. DOI: 10.1007/s00148-012-0423-y.

[3] Azarova, L.N. (2019). Gender-based approach in migrant children's education. In XII International Scientific Conference Proceedings of the Russian Association of Female History and Mikluho-Maklay Institute of Ethnology and Anthropology RAS. Kaliningrad. 2019. 259-262.

[4] Board on Children and Families (1995). Immigrant Children and Their Families: Issues for Research and Policy. The Future of Children, 5, 2, 72-89.
[5] Borisova, E.V. (2017). Children's mobility in the context of migration from Tajikistan. Sociological research, 8, 73-80, available at: http://socis.isras.ru/files/File/2017/2017_8/Bor isova.pdf.

[6] Bratsberg, B., Raaum, O., \& Røed, K. (2010). Educating children of immigrants: Closing the gap in Norwegian schools. Nordic Economic Policy Review, 1, 211-249.

[7] Brednikova, O.E., Sabirova, G.A. (2015). Children in migrant families: parental strategy in transnational contexts. Anthropological forum, 26, 127-152.

[8] Brinbaum, Y., Kieffer A. (2009). The schoolings of the children of immigrants of the sixth in baccalaureate: differentiation and polarization of courses, Population, 3, 64, 561-610. DOI: 10.3917/popu.903.0561.

[9] Britvina, I.B. (2006). Gender determination of adaptation of the compelled migrants: sociological analysis. The abstract of the thesis for a degree of the doctor of sociological sciences. Yekaterinburg, Ural Federal University, 39 p.

[10] Capps, R., Fix, M., \& Zong, J. (2017). The education and work profiles of the DACA population. Washington, DC, Migration Policy Institute Issue Brief. Available at: http://www.aacrao.org/docs/default-ource/TrendTopic/Imm igration/download.pdf?sfvrsn=0S.

[11] Dimitrova, R., Chasiotis, A. (2012). Are Immigrant Children in Italy Better Adjusted Than Mainstream Italian Children? In The Impact of Immigration on Children's Development. Contributions to Human Development, 24. Ed. by C.T. Garcia Coll. Basel: S. Karger AG, 153 p.

[12] Dobson, M.E. (2009). Unpacking children in migration research, Children's Geographies, 7.3, 355-360.

[13] Female migrants from the CIS countries in Russia (2011). Ed. by E.V. Tiuriukanova. Moscow, MAKS Press, 120 p.

[14] Ganushko, O.V. (2011). A comparative analysis of the problem of vocational training for teachers working with migrant children in Russia and Germany. Siberian pedagogical journal, 2, 261-268.

[15] Gender and migration (2017). International Organization for Migration (IOM). Available at: https://www.iom.int/gende r-and-migration.

[16] Gender equality (2018). European Commission. Available at: http://ec.europa.eu/justice/gender-equality/files/opinions_ad visory_committee/opinion_integration_migrants_en.pdf (accessed 6 March 2018).

[17] Goodburn, C. (2015). Migrant Girls in Shenzhen: Gender, Education and the Urbanization of Aspiration. China Quarterly, 222, 320-338. DOI:10.1017/S03057410150004 29.

[18] Immigrant Education in Finland (2005). Opetushallitus. Available at:http://www.oph.fi/download/47659_OPH_ma ahanmuu.ajaesite_envalmis.pdf.

[19] Kohanovskaja M.I. (2019). She is soon to be married: Gender aspects of migrant children's adaptation at school. In XII International Scientific Conference Proceedings of the Russian Association of Female History and Mikluho-Maklay Institute of Ethnology and Anthropology RAS. Kaliningrad. 2019. 268-271. 
[20] Koptseva, N.P., Bakhova, N.A., Zamaraeva, Yu.S., \& Kirko, V.I. (2012). The problem of sociocultural research in the modern humanity. Modern problems of science and education, 3, 323-330, available at: https://elibrary.ru/auth or_items.asp?authorid=626847.

[21] Krasil'nikova, O.V. (2014). Gender Differences and Determinants of the Acculturation Strategies among Russian-Speaking Immigrants in Germany. The Journal of Sociology and Social Anthropology, 17, 3, 77-93.

[22] Kurtz-Costes, A., Pungello, E.P. (2000). Acculturation and Immigrant Children: Implications for Educators. Social Education. 64, 2, 121-125.

[23] Llácer, A., Zunzunegui, M.V., del Amo, J., Mazarrasa, L. \& Bolůmar, F. (2007). The contribution of a gender perspective to the understanding of migrants' health. Journal of Epidemiology \& Community Health. 61 (Suppl. 2), 4-10. DOI: 10.1136/jech.2007.061770

[24] Madyukova, S.A., Persidskaya, O.A. (2017). Ethnic enclaves as a social and territorial phenomenon (on the example of Novosibirsk). Humanities \& Social Sciences, 10 (7), 983-994, available at: http://journal.sfu-kras.ru/article/ 33651.

[25] Makarov, A.Ya. (2010). Features of ethnocultural adaptation of children of migrants at the Moscow schools. Sociological research, 8, 94-101.

[26] Monastyrskaya, T.I., Kuzina, E.V., \& Kovaleva, A.A. (2016). Adaptation of migrant children in the educational environment: problems and possibilities of high school. Proceedings of the VI International scientific and practical conference "Specifics of ethnic migration processes in the territory of the Central Siberia in the 20-21st centuries: experience and prospects". Krasnoyarsk, 169-175.

[27] Omel'chenko, E. L., Andreeva, Yu. V., Luk'yanova, E. L., Sabirova, G. A., \& Krupets, Ya. N. (2010). Adaptation of children of migrants at school. Learner's guide: Recommendations about carrying out a complex of adaptation actions in general education organizations of the Russian Federation. Ul'yanovsk, 100 p.

[28] Pogodaev, N.P. (2017). Adaptation of students from Tajikistan in university space of Tomsk: in search of models and meanings. Humanities \& Social Sciences, 10 (7), 868-903, available at:http://journal.sfu-kras.ru/article/3365 1.

[29] Poletaev, D. (2012). Problems of training and adaptation of children migrants at the Moscow school. Ethnodialogues, 1 (38), 142-159.

[30] Qin, B.D. (2006). The Role of Gender in Immigrant Children's Educational Adaptation, In Current Issues in Comparative Education, 9 (1), 8-19.

[31] Qin, D.B. (2009). Being ‘Good' or Being 'Popular’: Gender and Ethnic Identity Negotiations of Chinese Immigrant Adolescents. In Journal of Adolescent Research. 24, 1, 3766.

[32] Sabirova, G.A., Andreeva, Yu.V. (2014). The school friendly company of the teenager with migration history. The Journal of Sociology and Social Anthropology, 1(72), XVII, 170-189.
[33] Savinov, L.V. (2017). Migration as a factor of regional policy in Siberian Federal District. Humanities \& Social Sciences, $10 \quad$ (7), 940-951, available at:http://journal.sfu-kras.ru/article/20205.

[34] Seminar on discussion of the Comprehensive program on adaptation and integration of migrants in the Novosibirsk region on November 17, 2017. (2017). Available at: http://www.sapanet.ru/?id=2537.

[35] Serebryanskaya, V.N. (2011) Gender in social communication. The Messenger of the Volgograd state university, Philosophy, 1 (13), 148-151.

[36] Seregina, I.N. (2013). Cultural and psychological features of children migrants: that the teacher needs to know also what with this knowledge to do. The Messenger of Practical Psychology of Education of MGPPU, 3, 69-71, available at: https://psy.su/feed/2635/.

[37] Shtyleva L.V. (2019). Cultural differences between ideals of schoolchildren's gender socialisation in Russia and Western countries. In XII International Scientific Conference Proceedings of the Russian Association of Female History and Mikluho-Maklay Institute of Ethnology and Anthropology RAS. Kaliningrad. 2019. 275-279.

[38] Starostina, L.D. (2013). Influence of gender features on motivation of the doctrine of teenagers. In Category "social" in modern pedagogics and psychology. Proceedings of scientific and practical conference (by correspondence) with the international participation. Ul'yanovsk, 263-267.

[39] Surovtsova, E.I. (2014). Accounting of gender features when training children from families of migrants. The historical and social and educational thought, 6, 6, 1, 151-153.

[40] Zamaraeva. Yu.S. (2011). The relation of the migrant and the accepting environment as a phenomenon of modern culture of Krasnoyarsk Krai (results of an associative experiment on the technique "Serial thematic associations"). Humanities \& Social Sciences, 4 (6), 805-815, available at: http://journal.sfu-kras.ru/article/2400.

[41] Zasypkin, V.P., Zborovskii, G.E., Shuklina, E.A. (2012) Problems of training and adaptation of children of migrants in figures and dialogues. Khanty-Mansiysk, Novosti Yugry, $212 \mathrm{p}$. 